\title{
BMJ Open Occupational class differences in long sickness absence: a register-based study of 2.1 million Finnish women and men in 1996-2013
}

\author{
Johanna Pekkala, ${ }^{1}$ Jenni Blomgren, ${ }^{2}$ Olli Pietiläinen, ${ }^{1}$ Eero Lahelma, ${ }^{1}$ \\ Ossi Rahkonen ${ }^{1}$
}

To cite: Pekkala J,

Blomgren J, Pietiläinen 0, et al. Occupational class differences in long sickness absence: a register-based study of 2.1 million Finnish women and men in 1996-2013. BMJ Open 2017;7:e014325. doi:10.1136/ bmjopen-2016-014325

- Prepublication history for this paper is available online. To view these files please visit the journal online (http://dx.doi. org/10.1136/bmjopen-2016014325).

Received 21 September 2016 Revised 29 May 2017

Accepted 6 June 2017

CrossMark

${ }^{1}$ Department of Public Health, University of Helsinki, Helsinki, Finland

${ }^{2}$ The Social Insurance Institution of Finland, Helsinki, Finland

Correspondence to

Dr Johanna Pekkala; johanna. pekkala@helsinki.fi

\section{ABSTRACT}

Objectives Sickness absence is consistently higher in lower occupational classes, but attempts to analyse changes over time in socioeconomic differences are scarce. We examined trends in medically certified sickness absence by occupational class in Finland from 1996 to 2013 and assessed the magnitude and changes in absolute and relative occupational class differences. Design Population-based, repeated cross-sectional study. Setting A 70\% random sample of Finns aged between 25 and 63 years in the years 1996-2013.

Participants The study focused on 25- to 63 year-old female (n between 572246 and 690 925) and male (n between 525698 and 644 425) upper and lower nonmanual and manual workers. Disability and old age pensioners, students, the unemployed, entrepreneurs and farmers were excluded. The analyses covered 2160084 persons, that is, $77 \%$ of the random sample. For primary and secondary outcome measures, we examined yearly prevalence of over 10 working days long sickness absence by occupational class. The Slope Index of Inequality (SII) and the Relative Index of Inequality (RII) were used to assess the magnitude and changes in occupational class differences.

Results Compared with mid-1990s, sickness absence prevalence was slightly lower in 2013 in all occupational classes except for female lower non-manual workers. Hierarchical occupational class differences in sickness absence were found. Absolute differences (SII) peaked in 2005 in both women $(0.12,95 \% \mathrm{Cl} 0.12$ to 0.13$)$ and men $(0.15,95 \% \mathrm{Cl} 0.14$ to 0.15$)$ but reached the previous level in women by 2009 and decreased modestly in men until 2013. Relative differences narrowed over time $(p<0.001)$ but levelled off by 2013.

Conclusions Sickness absence prevalence is currently slightly lower in almost all occupational classes than in the mid-1990s, but occupational class differences have remained large. III health and poor working conditions especially in the lower occupational classes should be targeted in order to reduce sickness absence and to achieve longer working lives.

\section{INTRODUCTION}

Sickness absence is a common public health and work life problem with social,
Strengths and limitations of this study

- Comprehensive register data of more than two million working-aged Finns in years 1996-2013.

- A nationally representative random sample was linked to data on medically certified long sickness absence with no missing information or self-report bias.

- Data on occupational class comprised information from a vast variety of occupations from various sectors.

- Both absolute and relative occupational class differences were examined.

- Due to lack of data on potential explanatory factors in the national registers, explanations for occupational class differences could not be studied.

psychological and financial consequences. It denotes temporal absence from work due to transient inability to perform one's tasks at work as a consequence of a disease or an injury. ${ }^{12}$ Sickness absence, especially if prolonged, reflects ill health and poor health-related functioning ${ }^{3} 4$ and predicts future permanent work disability. ${ }^{56}$ In Finland, sickness absence rate is higher compared with several other member countries of the Organisation for Economic Co-operation and Development (OECD). ${ }^{7}$ The total expenditure on sickness absence benefits accounted for $1.2 \%$ of the gross domestic product in 2007 compared with an OECD average of $0.8 \% .^{7}$

Previous studies from several countries have shown hierarchical occupational class differences in sickness absence across the occupational classes; that is, sickness absence is consistently higher in lower occupational classes. $^{8-15}$ Manual workers have approximately two to three times more sickness absence episodes than upper non-manual employees, ${ }^{13}$ and the differences tend to be 
larger in men. ${ }^{1011} 1314$ Occupational class as a key indicator of socioeconomic position reflects the disparities, for example, in working conditions between occupational classes. ${ }^{16}$ Although several previous investigations have shown clear hierarchical occupational class differences in sickness absence, less is known about the changes in the class differences over time. In Denmark, the occupational class differences in sickness absence among private sector employees persisted from mid-1970s to 2007. ${ }^{12}$ In Finland, occupational class differences in 3 or more days long sickness absence among municipal employees have remained over the last 20 years, although slightly narrowed in recent years. ${ }^{915}$ Moreover, studies examining the changes using broad representative populations covering the whole working-aged population are lacking. The external validity of the previous investigations conducted on specific workplace or work sector samples is limited, since they may not cover the full range of occupational classes and related working conditions with different job security in different ages. ${ }^{11}$

As the workforce is ageing, there is an increasing economic dependency ratio (ie, the number of non-employed persons per one employed person) in Finland as well as in several other European countries. ${ }^{17}$ Hence, extending working lives, for example, by reducing sickness absence, is regarded one of the key goals by the Finnish government and labour market organisations, ${ }^{18}$ with many other OECD countries. ${ }^{7}$ Western countries face many identical challenges in the attempts to reduce sickness absence, for instance, regarding existing occupational class differences in sickness absence and the major causes of long-term sickness absence. ${ }^{19}$ Evidence on trends over time in occupational class differences in sickness absence could help to detect potential changes in the high-risk groups, to identify potential causes for the changes and to execute preventive actions effectively and early enough in order to reduce sickness absence and postpone employees' permanent withdrawal from the labour market. Evaluating trends over time in occupational class differences in health is also crucial, for example, in assessing the impact of health and work life policy interventions. ${ }^{20}$ In Finland, several amendments to legislation were made in the early 2010 s to promote work ability, prevent work disability and enhance possibilities to return to work despite restrictions of work ability in cooperation with employees, employers and occupational health services. ${ }^{21}$ Furthermore, reducing health inequalities has been an integral part of many health policy programmes in Finland over the past few decades. ${ }^{22}$

Our aims were (1) to examine trends in medically certified sickness absence by occupational class among Finnish women and men from 1996 to 2013 in the national population and to assess (2) the magnitude and (3) changes over time in absolute and relative occupational class differences in sickness absence. There is a general consensus on the importance of assessing both absolute and relative differences when monitoring socioeconomic inequalities in health. ${ }^{20}{ }^{23-25}$ Absolute differences denote the public health significance, whereas relative differences are a better indicator of causal effects, for example, the magnitude of a relationship between a policy measure and the outcome. $^{23}{ }^{24}$ Further evidence on occupational class differences in sickness absence based on a nationwide working population could help to reveal the high-risk groups in terms of work ability, to allocate resources effectively and, thus, to extend working lives and reduce the costs of work disability.

\section{METHODS \\ Data}

A nationally representative $70 \%$ random sample of 25- to 63-year-old persons belonging to the Finnish population over the period of 1995-2012 was obtained from the register of the Social Insurance Institution of Finland (Kela). The format of the sample data is an unbalanced panel; depending on their age, migration and mortality, individuals could be included in the sample each year or they may move in and out of the dataset. However, the sample is equally representative of the Finnish population aged 25-63 at the end of each study year 1995-2012.

Year-end data on occupational class from the register of Statistics Finland were linked to the sample. Occupational class was based on the classification of socioeconomic groups of Statistics Finland. ${ }^{26}$ Occupational class was available for years 1995, 2000 and 2004-2012. Disability pensioners and old age pensioners were excluded, since they are not entitled to sickness allowance. Also, we excluded students, the unemployed, entrepreneurs and farmers. This study focused on three hierarchical occupational classes: upper non-manual employees, lower non-manual employees and manual workers (in total, 2160084 persons, that is about $77 \%$ of the sample).$^{26}$

Sickness absence was measured by sickness allowance episodes during the study period 1996-2013, derived from the register of Kela. In Finland, sickness allowance can be paid to persons aged 16-67 years (until 2004, 16-64 years) to compensate for work disability due to an illness or accident, lasting up to approximately 1 year. Sickness allowance is payable after a waiting period consisting of the first day of work disability and the following 9 working days (Sundays and midweek holidays are not counted). The waiting period is 55 calendar days for those who have not been working or engaged in any other gainful activity, that is, studying or being an unemployed jobseeker, during the preceding 3 months. ${ }^{27} \mathrm{~A}$ medical certificate is required in order to receive the benefit. The register data included the beginning and end dates of work disability, providing information on sickness absence episodes.

We thus examined sickness absence episodes lasting over 10 working days. In this study, sickness absence was measured by prevalence. Sickness absence was dichotomised as a binary outcome measure, in which one referred to those individuals having at least one sickness absence episode and 0 to persons with no absence episode during a calendar year. With regard to 
each calendar year, we included both ongoing sickness absence episodes from the previous year and those sickness absence episodes initiated during the calendar year in question, as suggested previously when calculating sickness absence prevalence. ${ }^{28}$ The population at risk for a sickness absence period during each calendar year was 25- to 63 year-old individuals in each occupational class at the end of the preceding year. For presentation purposes, the year-end population denotes the study population at the beginning of each study year. The upper age limit was set to make different study periods comparable in terms of age as there was a reform in age criterion for granting sickness allowance in 2005. The lower age limit was set to ensure a more stable occupational class of the persons in the sample. We examined all sickness allowance episodes based on any diagnostic cause.

\section{Ethics statement}

This study solely used secondary data retrieved from registers. Conventions of good scientific practice, data protection and information security have been applied. The study was based on registries, and thus, ethics approval was not required according to Finnish law. ${ }^{29}$

\section{Statistical methods}

We stratified all analyses by sex due to differences in sickness absence between women and men. We calculated the age-adjusted yearly prevalence for long-term sickness absence by occupational class annually for the years 1996, 2001 and 2005-2013 (ie, each calendar year being a cross-section with regard to time) due to the availability of data on occupational class in the ends of 1995, 2000 and from 2004 onwards. Age was directly standardised using 5 -year age groups, with the study population of 2005 as the standard population (women and men separately). Yearly age group-specific sickness absence prevalences were calculated after which age adjustment weights based on the standard population by 5 -year age grouping were added to the calculations for each occupational class. Age-standardised prevalence was presented as a percentage with $95 \%$ CI.

Time trend in sickness absence prevalence by occupational class was examined on data with all years pooled. Due to the format of the data, the same individuals could be measured repeatedly during the study period. A generalised estimating equations (GEE) method was used to take into account correlation within each individual due to repeated measurements over time. ${ }^{30}$ This was done for each occupational class separately by including sickness absence as a dependent variable and calendar year and age as continuous independent variables to the binomial models using SAS procedure proc genmod with an identity link function and an autoregressive correlation structure. We used autoregressive working correlation, since correlation between measurements of each individual was assumed to be smaller the farther in time the measurements were.
We estimated the Slope Index of Inequality (SII) and the Relative Index of Inequality (RII) in order to assess the magnitude of absolute and relative occupational class differences in sickness absence. SII and RII are recommended when making comparisons in the magnitude of socioeconomic inequalities over time. ${ }^{24} 3132$ These are regression-based summary measures and take simultaneously into account the size and relative socioeconomic position of all groups that are compared. SII and RII impose linearity on the association between occupational class and sickness absence.

In order to estimate SII and RII, ${ }^{24} 3132$ we first ordered the occupational classes from highest to lowest and then transformed the occupational class variable into a relative occupational rank indicator by calculating the midpoint of the range of each occupational class in the cumulative distribution. For instance, if upper non-manuals comprised $20 \%$ of the study population among women during a calendar year, the rank indicator for this occupational class would be $0.10(0.20 / 2)$. Furthermore, if the percentage of female lower non-manuals was $50 \%$, the rank indicator for this occupational class would be $0.45(0.20+0.50 / 2)$. The rank indicator could take values from 0 (the theoretical top of the class hierarchy) to 1 (the theoretical bottom of the class hierarchy).

The rank indicator was entered as a continuous independent variable in the binomial models, with an identity link function when calculating SII and a log-link function for RII. ${ }^{32}$ The SII implies the rate difference and the RII the rate ratio of having sickness absence between the theoretical bottom and top of the occupational class hierarchy. SII values above 0 indicate higher sickness absence prevalence in lower occupational classes and below 0 the opposite difference. RII values above 1.0 denote higher and values below 1.0 lower sickness absence prevalence in the lower compared with higher occupational classes. Age-adjusted SII and RII values for sickness absence and 95\% CI were calculated annually (ie, each calendar year being a cross-section with regard to time) for years 1996, 2001, 2005, 2009 and 2013, using age as a continuous independent variable in the models. The first 3 years were selected due to the availability of data on occupational class in the ends of 1995, 2000 and 2004 and then shown at 4-year intervals. To test for trends in absolute (SII) and relative (RII) occupational class differences in sickness absence, the GEE method was used. This was done by including calendar year and an interaction term of the rank indicator and calendar year in the aforementioned models on data with all years (ie, 1996, 2001 and 2005-2013) pooled using SAS procedure proc genmod with an identity link function for absolute differences and a log-link function for relative differences and an autoregressive correlation structure.

Statistical significance was defined as a $\mathrm{p}$ value $\leq 0.05$. All analyses were performed using SAS statistical software V.9.4. 
Table 1 Distribution of the study population by sex and occupational at the beginning of 1996, 2001, 2005, 2009 and 2013 (\% in parentheses)

\begin{tabular}{llllll}
\hline & 1996 & 2001 & 2005 & 2009 & $\mathbf{2 0 1 3}$ \\
\hline Women, aged 25-63 & & & & & \\
$\quad$ Manual workers & $159121(27.8)$ & $175289(27.8)$ & $155799(23.7)$ & $151977(22.0)$ & $130994(19.3)$ \\
\hline Lower non-manual & $301600(52.7)$ & $321450(50.9)$ & $351592(53.5)$ & $370407(53.6)$ & $380261(56.0)$ \\
\hline Upper non-manual & $111525(19.5)$ & $134714(21.3)$ & $149489(22.8)$ & $168541(24.4)$ & $167348(24.7)$ \\
\hline Total & $572246(100)$ & $631453(100)$ & $656880(100)$ & $690925(100)$ & $678603(100)$ \\
Men, aged 25-63 & & & & \\
$\quad$ Manual workers & $263363(50.1)$ & $301876(50.2)$ & $300067(48.6)$ & $302065(47.2)$ & $280704(46.0)$ \\
\hline Lower non-manual & $133850(25.5)$ & $152592(25.4)$ & $156777(25.4)$ & $158350(24.7)$ & $163703(26.8)$ \\
$\quad$ Upper non-manual & $128485(24.4)$ & $146436(24.4)$ & $160141(26.0)$ & $179820(28.1)$ & $165831(27.2)$ \\
\hline Total & $525698(100)$ & $600904(100)$ & $616985(100)$ & $640235(100)$ & $610238(100)$ \\
\hline
\end{tabular}

The study population for each year is equal to the population at the end of the preceding year.

The overall proportion of individuals having at least one sickness absence episode during a year ranged between $15 \%$ and $17 \%$ in women and between $10 \%$ and $12 \%$ in men, respectively.

\section{RESULTS}

In table 1, the occupational class distribution of the study population is presented for years 1996, 2001, 2005, 2009 and 2013. Throughout, the largest occupational class was lower non-manuals for women and manual workers for men. In both women and men, the proportion of manual workers decreased, and the proportion of both lower and upper non-manuals increased from the mid-1990s to 2013.

The sickness absence prevalence remained broadly stable from the mid-1990s to the early 2000s, after which an increase took place until 2005/2006 in all occupational classes (figure 1). The strongest increase was found among lower non-manuals among both women and men. After 2005/2006, sickness absence prevalence turned into a modest decrease. It reached the lowest level in 2013 in almost all occupational classes. Lower non-manual women were the only group with a higher prevalence at the end of the study period compared with the mid-1990s ( $p$ for trend $<0.001$ ). The prevalence was lower in 2013 than in 1996 in all other studied occupational classes ( $p$ for trend $<0.001$ ); for lower non-manual men, there was moderate evidence of change over time ( $\mathrm{p}$ for trend $0.0519)$. Lower occupational class was consistently related to higher sickness absence prevalence among both women and men between 1996 and 2013. Throughout, manual workers had approximately two times higher prevalence of sickness absence compared with upper non-manuals.

Age-adjusted absolute occupational class differences in sickness absence measured by the SII were clear and fairly stable over time (table 2). In women, the prevalence of sickness absence was 11 percentage points higher among manual workers than among upper non-manuals both in 1996 (SII 0.11, 95\% CI 0.11 to 0.12) and 2013 (SII 0.11, $95 \%$ CI 0.11 to 0.12 ). As for men, the corresponding figures were 13 percentage points (SII $0.13,95 \%$ CI 0.13 to 0.14 ) and 11 percentage points (SII $0.11,95 \%$ CI 0.11 to 0.12 ), suggesting a modest tendency of decline over
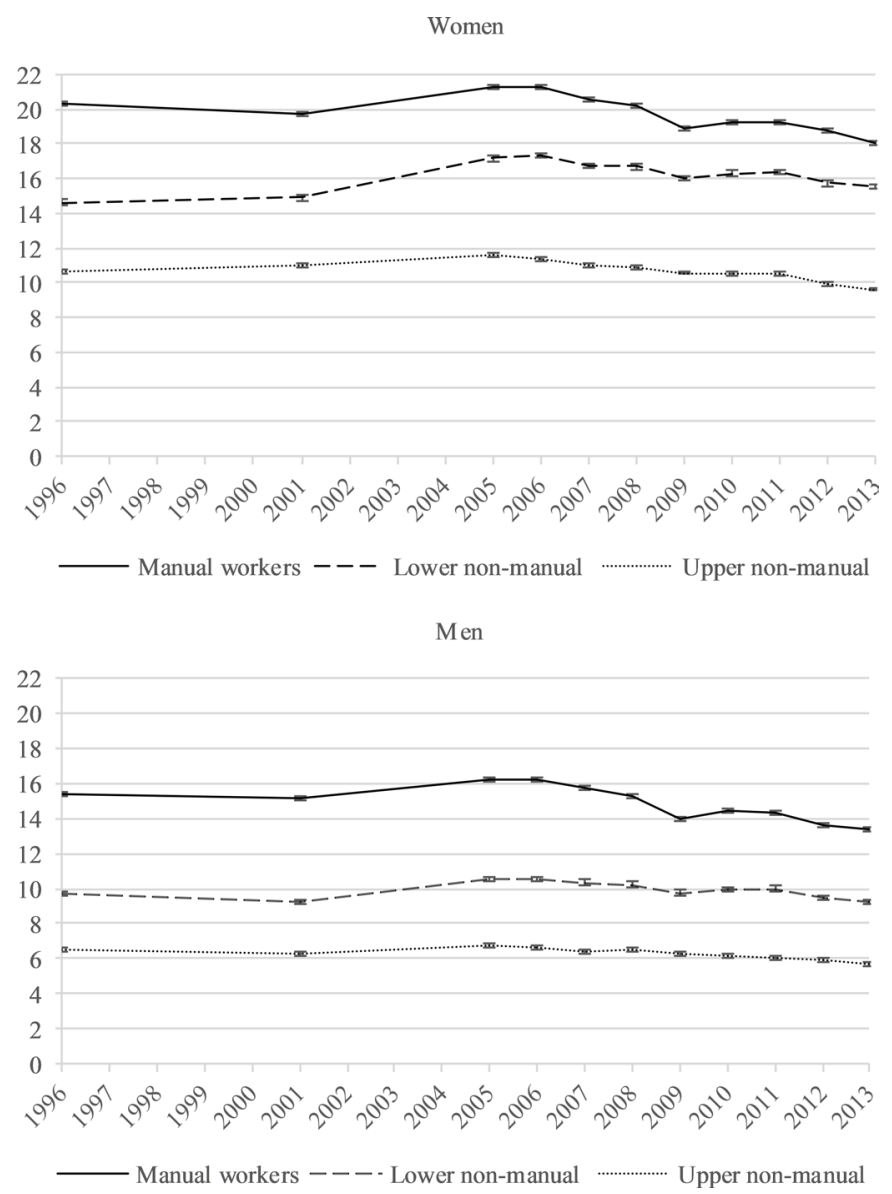

Figure 1 Age-adjusted prevalence (\%) of medically certified sickness absence by occupational class among women and men aged 25-63years in Finland from 1996 to 2013. Adjusted by the direct method, with 2005 as the standard population. Error bars represent the $95 \% \mathrm{Cl}$. Error bars not shown if information on occupational class that year was missing. 
Table 2 Age-adjusted SII* and RII† of medically certified sickness absence $(95 \% \mathrm{Cl})$ by occupational class among women and men aged 25-63 years in Finland 1996, 2001, 2005, 2009 and 2013

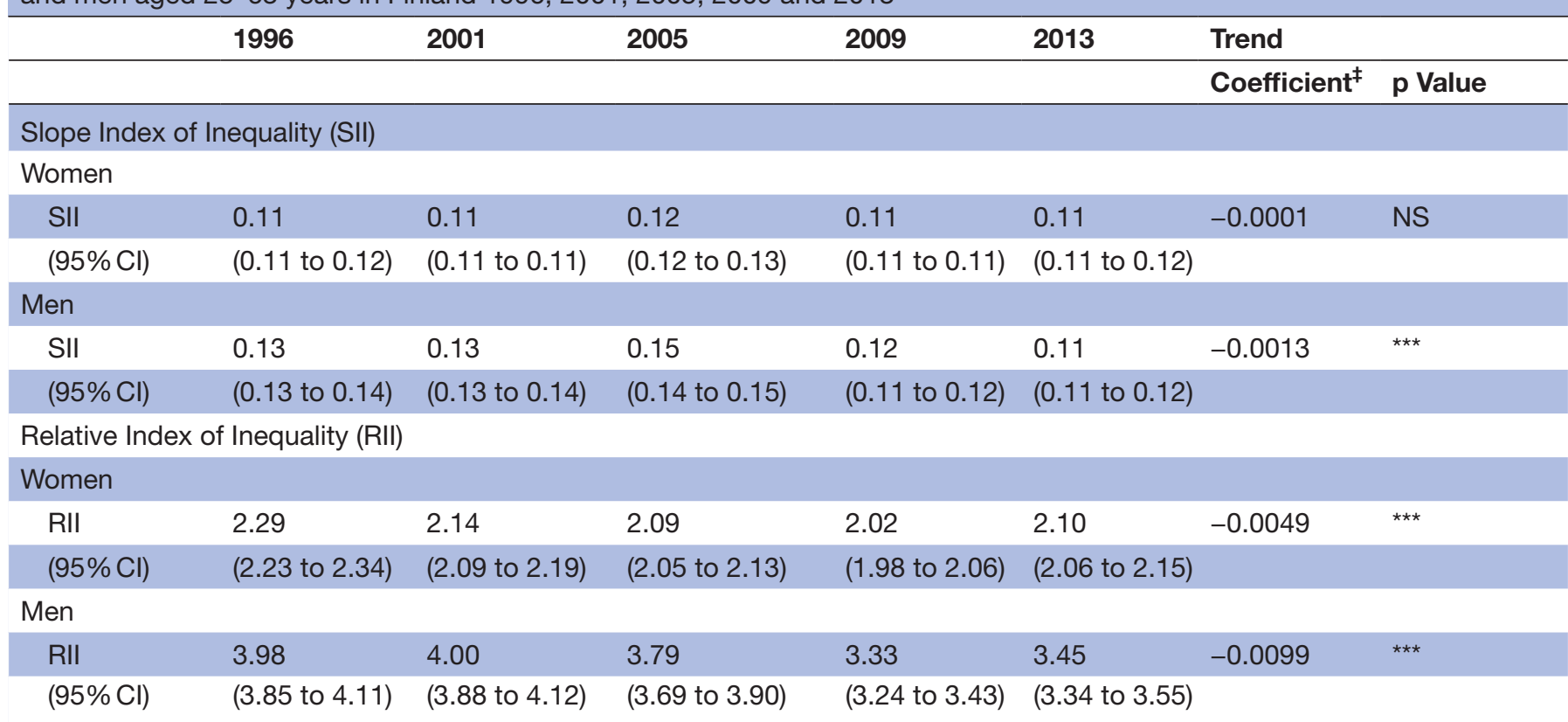

${ }^{*} \mathrm{p}<0.05 ;{ }^{* *} \mathrm{p}<0.01 ;{ }^{* \star *} \mathrm{p}<0.001 ; \mathrm{NS}$, statistically non-significant.

*Slope Index of Inequality, by log-binomial regression using an identity link function.

tRelative Index of Inequality, by log-binomial regression using a logarithmic link function.

$\ddagger$ The coefficient of the interaction term of the relative occupational rank indicator and calendar year. OR ( $95 \% \mathrm{Cl})$ for the trend in RII: 0.9951

(0.9936 to 0.9965 ) for women and 0.9902 (0.9883 to 0.9921 ) for men.

time in absolute differences $(\mathrm{p}<0.001)$. An increase in SII values took place in 2005 in both women and men, thus indicating a temporal widening in absolute occupational class differences in sickness absence simultaneously with the increase in prevalence.

Clear relative occupational class differences in sickness absence were found throughout the study period (table 2). However, age-adjusted relative differences (RII) narrowed both in women $(\mathrm{p}<0.001)$ and men $(\mathrm{p}<0.001)$ over time. In women, the age-adjusted RII was slightly lower in 2013 (RII 2.10, 95\% CI 2.06 to 2.15) than 1996 (RII 2.29, 95\% CI 2.23 to 2.34). Also in men, the relative differences were smaller in 2013 (RII 3.45, 95\% CI 3.34 to 3.55) than 1996 (RII 3.98, 95\% CI 3.85 to 4.11). However, the narrowing trend in relative differences reversed slightly between 2009 and 2013 in both sexes.

\section{DISCUSSION}

\section{Main findings of the study}

This study examined trends in medically certified sickness absence by occupational class among Finnish women and men aged 25-63 from 1996 to 2013 and assessed the magnitude and changes over time in absolute and relative occupational class differences in sickness absence. The main findings were as follows: (1) In all occupational classes, sickness absence prevalence remained fairly stable in the late 1990s but increased from the millennium until 2005/2006, particularly among lower non-manual women, after which a downward turn occurred. (2) Clear occupational class differences were found, with higher sickness absence prevalence in lower occupational classes in both women and men over time. (3) Absolute differences were evident and widened temporarily in 2005, after which they reached the previous level in women and narrowed until 2013 in men. (4) Relative differences were large, especially among men, and narrowed over time, although the decreasing trend levelled off between 2009 and 2013.

\section{Strengths and limitations of the study}

This study has several strengths. Data of more than two million working-aged persons were drawn from comprehensive and reliable national registers. A representative random sample of Finnish working aged population in 1995-2012 was employed and linked to data on medically certified sickness absence with practically no missing information or self-report bias. Furthermore, data on occupational class, that is, manual workers and lower and upper non-manual employees, were based on the classification of Statistics Finland comprising information from a vast variety of occupations from various sectors. Thus, the results can be generalised to the Finnish labour force with respect to the occupational classes studied.

In this study, explanations for occupational class differences could not be studied due to lack of information on potential explanatory factors, such as working conditions, in the national register data. Moreover, there are no comprehensive nationwide registers on short sickness absence periods in Finland. However, all longer, medically 
certified periods exceeding 10 working days, measured through sickness allowance paid by Kela, can be obtained from the national registers. Based on the results from previous Finnish studies covering also short sickness absence episodes, ${ }^{91533}$ the analyses would probably have shown a raise in the prevalence of sickness absence in the late 1990s and an even more steeply increasing trend in the sickness absence prevalence in lower non-manuals in the early 2000s, if shorter absence periods could have been assessed simultaneously with the longer ones. Also, the analyses might have revealed more nuanced trends in the late 1990s and early 2000s, if information on occupational class in 1996-1999 and 2001-2003 would have been available.

\section{Comparison with the literature regarding changes over time in sickness absence by occupational class}

Part of the variation in sickness absence prevalence in all occupational classes is likely to be explained by changes in business cycles. Several studies have shown that sickness absence is procyclical, that is, the absence rate increases in the periods of economic boom and declining unemployment rate. At least two mechanisms may contribute: employment of workers with poorer health and higher tendency to be absent and changes in absence behaviour due to less fear of job loss, during economic booms, and vice versa. ${ }^{34}$ This has been supported also by previous findings in Finland. Sickness absence (4+ days) increased in all occupational groups among municipal employees in the late 1990s simultaneously with the recovery of the national economy and declining unemployment rate after the deep recession in Finland in the early 1990s. ${ }^{9}$ Unemployment rate continued to decline in Finland from the late 1990s until $2008,{ }^{35}$ after which an economic downturn occurred. ${ }^{36}$ The increasing trend in sickness absence among municipal employees persisted in early 2000s until 2008, after which a downward trend took place. ${ }^{15}$

The present study showed that sickness absence prevalence was fairly stable in the late 1990s and did not start to increase until the early 2000s. One explanation might be that, unlike in previous studies, we included both public and private sector employees in the analyses. Approximately $65 \%$ of the Finnish employees work in the private sector. ${ }^{37}$ On average, private sector employees have found to be less absent from work compared with public sector workers during high unemployment. ${ }^{38}$ The unemployment rate remained at a relatively high level in the late 1990 s, that is, approximately $10 \%, 35$ which may have led to a persistent job insecurity and, thus, maintenance of low sickness absence among private sector workers. Unemployment continued to decline in the early 2000s in concordance with increasing sickness absence prevalence in all occupational classes. Procyclicality is previously detected in long-term sickness absence with a medical diagnosis and certification. ${ }^{39}$ Finally, amendments to sickness insurance legislation during the study period may have affected the results only marginally, ${ }^{27}{ }^{40}$ since the legislative changes did not affect the study population to any substantial degree.

\section{Comparison with the literature regarding magnitude and changes over time in occupational class differences in} sickness absence

Occupational class differences in sickness absence found in this study parallels results obtained from other studies. ${ }^{8-15}$ Previous studies have shown that physical working conditions contribute to the occupational class differences in sickness absence. ${ }^{810111314}$ In a Swedish study, physical work exposures explained the entire association in women. ${ }^{14}$ The results regarding the contribution of psychosocial working conditions have been heterogeneous ${ }^{811} 13$ and differed between women and men. ${ }^{10}$ Additionally, occupational class differences in sickness absence have been partly explained by health behaviours ${ }^{10} 13$ and, to some extent, by family-related factors (ie, social support and having children in the family) in men. ${ }^{13}$ Besides adverse individual and workplace related factors, also determinants at a community level may affect the association; a British study ${ }^{41}$ found that employees working in more socially deprived communities had a higher rate of sickness absence than those working in more affluent areas. Working in socially deprived areas was hypothesised to be either a cause of work stress or reflect more disadvantageous backgrounds of employees working and living in these areas. ${ }^{41}$

This study showed that absolute occupational class differences in sickness absence were fairly stable in the late 1990s but widened temporarily in the early 2000 s in concordance with increasing sickness absence prevalence in all studied groups. This was mainly explained by more rapidly increasing sickness absence in lower occupational classes, especially among female lower non-manuals. Previous studies have found an increasing trend in short (1-3 days) sickness absence among Finnish lower non-manual municipal employees. ${ }^{153}$ This study showed an increasing trend in the prevalence of long-term sickness absence among female lower non-manuals, whereas a decreasing trend appeared in other occupational classes in both genders. This may be partly due to a considerable change in occupational structure in Finland over time,${ }^{42}$ as shown also in this study (table 1 ). In women, the growth has taken place, for example, in healthcare work, ${ }^{42}$ with both physically and mentally demanding lower non-manual occupations, such as nurses. In spite of these adverse changes in sickness absence prevalence after the millennium, the relative occupational class differences narrowed in the early 2000s in both genders. The widening of the absolute differences was not large enough to be reflected in the relative class differences. ${ }^{25}$ For women, a modest downward trend in the relative class differences was observed already in the late 1990s.

Despite of the temporal widening of absolute differences in the early 2000s, the differences reached the previous level in women until 2009. The test for trend showed stable absolute differences among women over the whole study 
period. Among men, the absolute differences continued to narrow until the end of the study period after a transient widening in the mid-2000s. The narrowing trend was partially due to more rapidly decreasing sickness absence among manual workers between 2006 and 2009. The result is similar to a previous Finnish study finding a narrowing trend in long (4+ days) sickness absence between manual workers and other occupational groups in the municipal sector in 2002-2013. ${ }^{15}$ One explanation for the change might be that, in recent years, the physical demands of work have been alleviated. ${ }^{37}$ Work is more physically demanding in manual occupations, and $73 \%$ of Finnish female manual workers considered their job physically demanding in $2008 .{ }^{42}$ The corresponding figure was $66 \%$ in $2013 .{ }^{37}$ Furthermore, awareness of occupational health and safety regulations has grown among employees over time. ${ }^{37}$ On the other hand, unemployment began to grow in Finland after 2008. ${ }^{35}$ Increased job insecurity may have led to decrease in sickness absence in lower occupational positions. ${ }^{43}$ Socioeconomic differences in morbidity and health behaviours, though, have remained evident. ${ }^{45}$

\section{Implications of the study and future research}

This study showed that sickness absence prevalence was slightly lower in 2013 than in the mid-1990s in almost all occupational classes. Clear occupational class differences in long sickness absence were found, and the class differences remained evident during the 20-year study period. However, there appeared a slight decrease in the class differences over time. A modest narrowing trend in both absolute and relative class differences took place among men, previously considered to be a sign of development toward the narrowing of disparities. ${ }^{25}$ Among women, the relative class differences declined slightly over time. In the early 2010s, several amendments to Finnish legislation were made to enhance promotion of work ability and prevent early exit from the labour market. ${ }^{21}$ This study showed that the declining trend in the relative differences levelled off by 2013 in both genders. Preventive measures should be continued and targeted to lower occupational classes and to manual workers in particular in the attempts to reduce sickness absence and narrow the occupational class differences in the future. The actions should be focused particularly on the major determinants causing the class differences in sickness absence, that is, health behaviours (such as smoking and overweight), psychosocial working conditions (especially job control) and physical work factors (such as hazardous exposures, physical work load and physical strain). ${ }^{13}$ Evaluation of the recent interventions and adverse trend in relative occupational class differences observed in this study call for monitoring the class differences in the future.

\section{CONCLUSIONS}

This study showed that sickness absence was slightly lower in 2013 than in the mid-1990s in all occupational classes except for female lower non-manuals. Both absolute and relative occupational class differences in sickness absence have remained evident over time. High levels of sickness absence are a burden on many levels of the society. Ill health and poor working conditions especially in the lower occupational classes should be targeted in order to reduce sickness absence and its costs and to achieve longer working lives.

Contributors JP participated in planning the study, conducted the statistical analyses, interpreted the results, wrote the first draft of the manuscript and all the later versions and approved the final manuscript as submitted. JB contributed to the planning of the study, interpreted the results, reviewed and revised the manuscript and approved the final manuscript as submitted. OP participated in planning the study, conducted the statistical analyses, interpreted the results, reviewed and revised the manuscript and approved the final manuscript as submitted. EL and OR contributed to the planning of the study, interpreted the results, reviewed and revised the manuscript and approved the final manuscript as submitted.

Funding This work was supported by The Social Insurance Institution of Finland (grant 67/26/2014), University of Helsinki (grant 73715702), the Strategic Research Council of the Academy of Finland (grant 293103/2015), and the Academy of Finland (grant 294514/2016).

Competing interests None declared.

Patient consent This study solely used secondary data retrieved from registers.

Ethics approval This study solely used secondary data retrieved from registers, and thus, ethics approval was not required according to Finnish law.

Provenance and peer review Not commissioned; externally peer reviewed. Data sharing statement № additional data are available.

Open Access This is an Open Access article distributed in accordance with the Creative Commons Attribution Non Commercial (CC BY-NC 4.0) license, which permits others to distribute, remix, adapt, build upon this work non-commercially, and license their derivative works on different terms, provided the original work is properly cited and the use is non-commercial. See: http://creativecommons.org/ licenses/by-nc/4.0/

(C) Article author(s) (or their employer(s) unless otherwise stated in the text of the article) 2017. All rights reserved. No commercial use is permitted unless otherwise expressly granted.

\section{REFERENCES}

1. Alexanderson K, Norlund A. Swedish Council on Technology Assessment in Health Care (SBU). Chapter 1. Aim, background, key concepts, regulations, and current statistics. Scand J Public Health Supp/ 2004;63:12-30.

2. Prins R. Sickness absence and disability: an international perspective. In: Loisel P, Anema JR, eds. Handbook of Work Disability: Prevention and Management. New York: Springer, 2013:3-14.

3. Marmot M, Feeney A, Shipley M, et al. Sickness absence as a measure of health status and functioning: from the UK Whitehall II study. J Epidemiol Community Health 1995;49:124-30.

4. Laaksonen M, Kääriä SM, Leino-Arjas $P$, et al. Different domains of health functioning as predictors of sickness absence-a prospective cohort study. Scand J Work Environ Health 2011;37:213-8.

5. Kivimäki M, Forma P, Wikström J, et al. Sickness absence as a risk marker of future disability pension: the 10-town study. J Epidemiol Community Health 2004;58:710-1.

6. Alexanderson K, Kivimäki M, Ferrie JE, et al. Diagnosis-specific sick leave as a long-term predictor of disability pension: a 13-year follow-up of the GAZEL cohort study. J Epidemiol Community Health 2012;66:155-9.

7. Sickness, disability and work: Breaking the barriers. A synthesis of findings across OECD countries. Paris, France: OECD, 2010.

8. Melchior M, Krieger N, Kawachi I, et al. Work factors and occupational class disparities in sickness absence: findings from the GAZEL cohort study. Am J Public Health 2005;95:1206-12.

9. Piha K, Martikainen P, Rahkonen O, et al. Trends in socioeconomic differences in sickness absence among Finnish municipal employees 1990-99. Scand J Public Health 2007;35:348-55. 
10. Christensen KB, Labriola M, Lund T, et al. Explaining the social gradient in long-term sickness absence: a prospective study of Danish employees. J Epidemiol Community Health 2008;62:181-3.

11. Hansen $\mathrm{H}-\mathrm{T}$, Ingebrigtsen $\mathrm{T}$. Social class and sickness absence in Norway. Acta Sociol 2008;51:309-27.

12. Johansen K, Bihrmann K, Mikkelsen S, et al. Trends in sickness absence in Denmark. Scand J Work Environ Health 2009;35:334-41.

13. Laaksonen M, Piha K, Rahkonen O, et al. Explaining occupational class differences in sickness absence: results from middle-aged municipal employees. J Epidemiol Community Health 2010;64:802-7.

14. Löve J, Hensing G, Holmgren $\mathrm{K}$, et al. Explaining the social gradient in sickness absence: a study of a general working population in Sweden. BMC Public Health 2013;13:545.

15. Sumanen $\mathrm{H}$, Piha $\mathrm{K}$, Pietiläinen $\mathrm{O}$, et al. Socioeconomic differences in sickness absence among city of Helsinki personnel in 2002-2013 (in Finnish). Finnish Medical Journal 2015;70:139-45.

16. Galobardes B, Shaw M, Lawlor DA, et al. Indicators of socioeconomic position (part 1). J Epidemiol Community Health 2006;60:7-12.

17. European Commission, The Economic Policy Committee. The 2015 Ageing Report: Underlying Assumptions and Projection Methodologies. European Economy 8: European Union, 2014. http:// ec.europa.eu/economy_finance/publications/european_economy/ 2014/pdf/ee8_en.pdf. (accessed 16 Aug 2016).

18. Ehdotuksia työurien pidentämiseksi. Työelämäryhmän loppuraportti 1.2.2010 (in Finnish). http://ttk.fi/files/1661/TEResitys010210.pdf. (accessed 18 May 2015).

19. Henderson M, Glozier N, Holland Elliott K, et al. Long term sickness absence. BMJ 2005;330:802-3.

20. Mackenbach JP, Kunst AE. Measuring the magnitude of socioeconomic inequalities in health: an overview of available measures illustrated with two examples from Europe. Soc Sci Med 1997;44:757-71.

21. Sauni R, Kivekäs J, Uitti J. Uudet työkyvyttömyyseläkkeet ovat vähentyneet neljänneksen (in Finnish). Finnish Medical Journal 2015;45:3056-7.

22. Palosuo $\mathrm{H}$, Koskinen $\mathrm{S}$, Lahelma $\mathrm{E}$, et al. Health inequalities in Finland: trends in socioeconomic health differences 1980-2005. Helsinki, Finland: Ministry of Social Affairs and Health, 2009.

23. Regidor E. Measures of health inequalities: part 2. J Epidemiol Community Health 2004;58:900-3.

24. Shaw M, Galobardes B, Lawlor DA, et al. The handbook of inequality and socioeconomic position. Concepts and measures. Bristol, UK: The Policy Press, 2007.

25. Moonesinghe R, Beckles GL. Measuring health disparities: a comparison of absolute and relative disparities. PeerJ 2015;3:e1438.

26. Statistics Finland. Classification of Socio-economic Groups 1989. http://stat.fi/meta/luokitukset/sosioekon_asema/001-1989/koko_ luokitus_en.html. (accessed 16 Aug 2016).

27. The Social Insurance Institution of Finland. Statistical Yearbook of the Social Insurance Institution 2014. Helsinki: The Social Insurance Institution of Finland, 2015.
28. Hensing $\mathrm{G}$. The measurements of sickness absence-a theoretical perspective. Norsk Epidemiologi 2009;19:147-51.

29. Finnish Advisory Board on Research Integrity. Ethical review in human sciences. http://www.tenk.fi/en/ethical-review-in-humansciences. (accessed 23 May 2017).

30. Lee JH, Herzog TA, Meade CD, et al. The use of GEE for analyzing longitudinal binomial data: a primer using data from a tobacco intervention. Addict Behav 2007;32:187-93.

31. Khang YH, Yun SC, Lynch JW. Monitoring trends in socioeconomic health inequalities: it matters how you measure. BMC Public Health 2008;8:66.

32. Ernstsen L, Strand BH, Nilsen SM, et al. Trends in absolute and relative educational inequalities in four modifiable ischaemic heart disease risk factors: repeated cross-sectional surveys from the Nord-Trøndelag Health Study (HUNT) 1984-2008. BMC Public Health 2012;12:266.

33. Sumanen H, Lahti J, Lahelma E, et al. 12-year trends in occupational class differences in short sickness absence among young women. Scand J Public Health 2015;43:441-4.

34. Pichler S. Sickness absence, moral hazard, and the business cycle. Health Econ 2015;24:692-710.

35. Statistics Finland. Labour market. http://tilastokeskus.fi/tup/suoluk/ suoluk_tyoelama_en.html. (accessed 10 Aug 2016).

36. Statistics Finland. Gross domestic product (GDP) at market prices 1975-2015. http://tilastokeskus.fi/til/vtp/2015/vtp_2015_2016-03-16_ tau_001_en.html. (accessed 10 Aug 2016).

37. Sutela H, Lehto A. Työolojen muutokset 1977-2013 (in Finnish). Helsinki, Finland: Statistics Finland, 2014.

38. Pfeifer C. Cyclical absenteeism among private sector, public sector and self-employed workers. Health Econ 2013;22:366-70.

39. Askildsen JE, Bratberg E, Nilsen OA. Unemployment, labor force composition and sickness absence: a panel data study. Health Econ 2005;14:1087-101.

40. Blomgren J. Pitkät sairauspoissaolot työikäisillä naisilla ja miehillä. Sairauspäivärahansaajat 1996-2015 (in Finnish). Yhteiskuntapolitiikka 2016;81:681-91.

41. Wynn P, Low A. The effect of social deprivation on local authority sickness absence rates. Occup Med 2008;58:263-7.

42. Lehto A, Sutela $\mathrm{H}$. Three decades of working conditions. Findings of Finnish Quality of Work Life Surveys 1977-2008. Helsinki, Finland: Statistics Finland, 2009.

43. Grunberg L, Anderson-Connolly R, Greenberg ES. Surviving layoffs: the effects on organizational commitment and job performance. Work Occup 2000;27:7-31.

44. Koskinen S, Martelin T, Sainio P, et al. et alChronic morbidity. In: Palosuo H, Koskinen S, Lahelma E, , eds. Health inequalities in Finland. Trends in socioeconomic health differences 1980-2005. Helsinki, Finland: Ministry of Social Affairs and Health, 2009:70-82.

45. Helldán A, Helakorpi S, Virtanen S, et al. Health Behaviour and Health among the Finnish Adult Population, Spring 2013 (in Finnish). Tampere, Finland: National Institute for Health and Welfare, 2013. 